\title{
Immunotherapy of Tuberculosis with IgA and Cytokines
}

\author{
Rajko Reljic ${ }^{1}$ and Juraj Ivanyi ${ }^{2}$ \\ ${ }^{1}$ Clinical Sciences Division, St George's, University of London, \\ ${ }^{2}$ Clinical and Diagnostic Sciences Department, Kings College London, \\ Guy's Campus of Kings College London \\ $G B$
}

\section{Introduction}

Immunotherapy of tuberculosis (TB) has long been considered to be a potential adjunct to chemotherapy, by targeting 'persister' organisms which are generated during chemotherapy. In this chapter, we briefly review the current immunotherapeutic approaches in $\mathrm{TB}$ and then focus in more detail on a novel form of combined immunotherapy (CIT), comprising an IgA monoclonal antibody (mAb) against the $\alpha$ crystallin (Acr) antigen, IFN- $\gamma$ and anti-IL-4 antibodies. CIT treatment significantly reduced new pulmonary infection and also the post-chemotherapy relapse in Mycobacterium tuberculosis infected BALB/c mice. Translation of this approach toward application in humans has been advanced by the development and characterization of a novel human IgA1 mAb which was generated by co-transfecting the $\mathrm{V}$ domains of the Acr-binding 2E9 scFv clone and IgA1 constant region domains into CHO-K1 cells. The monomeric 2E9IgA1 has strong binding affinities for Acr and for the human FcaRI/CD89 receptor. Intranasal inoculation of affinity purified 2E9IgA, and mouse IFN- $\gamma$ inhibited M. tuberculosis pulmonary infection and granuloma formation in the lungs of CD89 transgenic, but not in littermate control mice. 2E9IgA1 also inhibited infection of human whole blood and monocyte cultures. Demonstration of the mandatory role of the Fc $\alpha$ RI/CD89 receptor for passive protection is novel and important for the elucidation of mechanisms of IgA action. Further development of the described new human $\mathrm{mAb}$ is required for the translation of immunotherapy for the control of TB in humans.

\section{Immunotherapy of TB}

TB is a major killer, causing 1.5 million deaths annually, with the majority occurring in developing countries, also bearing the brunt of the rampant HIV epidemic. Although TB chemotherapy is highly effective, it is very protracted, lasting for six months or longer. This impacts negatively on completion rates, and defaulting leads to the emergence and spread of multi-drug resistant (MDR) strains of tubercle bacilli. Although new drugs have been proposed for treatment [1], the need for new therapies is of major concern in the fight against the MDR-TB. Arresting the global TB epidemic and also reducing the incidence of 
MDR-TB could be achieved by shortening the duration of the treatment. Since combined drug and immunotherapy treatments probably carry the greatest potential, several immunotherapeutic approaches have been considered, with the three described below receiving most attention.

\subsection{Immunotherapeutic vaccines}

One of the first immunotherapeutic applications of vaccines to show some promise in a clinical trial was the heat-killed Mycobacterium vaccae [2]. Its mode of action has been proposed to be an enhancement of Th1 and down-regulation of Th2 cytokine expression. Multiple doses of vaccine are required to achieve faster bacteriological conversion, improved radiological picture and recovery of body weight. However, subsequent clinical trials with M. vaccae produced inconclusive (reviewed in [3]), or negative results [4, 5]. Plasmid DNA expressing mycobacterial antigens have also been evaluated for their therapeutic capacity. Thus, Hsp65-based DNA vaccine prevented the post-chemotherapy relapse in mice [6], while an Ag85-expressing DNA vaccine was effective in one [7], but not in another [8] study. A detoxified extract of M. tuberculosis in liposome form (termed RUTI), prevented post-chemotherapy relapse in the 'Cornell model', and was proposed for the immunoprophylactic treatment of latent tuberculous infection [9]; this vaccine has recently undergone a phase 1 clinical trial in Spain (Cardona-PJ, personal communication).

\subsection{Cytokine therapy}

Cytokines are highly pleiotropic proteins that can promote host immune defence mechanisms. For effective treatment of mycobacterial infections, the administered cytokines must first reach their target cells, bind to the specific receptors and finally, activate an intact signal transduction pathway to elicit a cellular response. Due to their pleiotropic activities, the dose and route of administration must be carefully considered, in order to avoid the risk of toxicity and other unwanted pharmacological effects. Several cytokines have been considered for treatment of mycobacterial infections, including IFN- $\gamma$, Il-2, IL-12, GM-CSF (granulocyte-macrophage colony-stimulating factor) and G-CSF (granulocyte colonystimulating factor). In TB patients, Th1 cytokines are produced at high levels at the site of infection, but the systemic response is characterised by high levels of Th2 and reduced levels of Th1 cytokines [10, 11]. Given the established protective role of Th1 immunity to intracellular pathogens, this provides a strong rationale for using these cytokines as immunotherapeutic adjunct treatment for TB. Two small clinical trials utilising recombinant IL-2 reported a definitive benefit in TB patients $[12,13]$. However, a subsequent large-scale randomized IL-2 trial of HIV-negative TB patients yielded disappointingly negative results. Paradoxically, it even appeared that IL-2 had a detrimental effect on bacillary clearance, probably due to IL-2-mediated induction of CD25 + regulatory T cells [14]. These studies show that although the cytokines carry a significant therapeutic potential, their application for treatment of TB is yet to be fully explored.

\subsection{Monoclonal antibodies}

Historically, the view that protective immunity against TB is imparted exclusively by T cells, but not by antibodies has been influenced by the assumption that antibodies cannot reach 
the bacilli which shelter within the phagosomes of infected macrophages. However, a review of the early literature on passive 'serum therapy' indicates both positive and negative results[15], with the one consistent theme being that such treatments appeared more effective in patients with early and localised TB rather than long-standing, chronic cases. With the development of modern approaches and tools, most notably the monoclonal antibody technology, it became possible to address the role of antibodies in intracellular infections in a far more controlled, reproducible fashion. Thus, significant new evidence emerged that antibodies can play a role in suppressing intracellular infections, including those caused by Cryptococcus neoformans [16], Listeria monocytgenes [17] and Erlichia chaffensis [18]. This led to a reappraisal of the role of antibodies in $\mathrm{TB}$, which has recently been reviewed by us [19] and others [15, 20]. However, this approach still remains contentious, and further work is clearly needed to address the role of antibodies and their potential therapeutic application in TB and other intracellular infections.

\section{Evidence for a therapeutic potential of antibodies in TB}

The possible protective role of antibodies in M. tuberculosis infection has been indicated by clinical studies, showing that antibody titres to LAM [21] or Ag85 antigens [22] were higher in patients with milder forms of active TB. Support for a protective role comes also from animal experiments showing higher level of infection in mice genetically depleted of $B$ cells ( $\mu$-chain knock-out)[23] or defective for IgA production [24].

Recently, a significant 100-fold reduction of the postchemotherapy relapse of pulmonary infection in SCID mice was reported following intraperitoneal inoculation of mouse antisera containing predominantly IgG antibodies [25]. These antibodies were stimulated by $M$. tuberculosis infection, chemotherapy and immunization of DBA/2 mice with a detoxified $M$. tuberculosis extract. In addition, intraperitoneal administration of a standard preparation of human gamma globulin from normal donors, reduced bacterial loads in the spleen and lungs of intravenously infected mice [26]. Antibodies could have played a role, since normal human sera contain high antibody titres for LAM and mycobacterial heat shock proteins [27].

Passive inoculation of mouse monoclonal antibodies $(\mathrm{mAb})$ against a number of antigens was reported to be protective in mouse models of TB infection, but the mechanisms involved differed. Thus, pre-opsonization of intratracheally administered tubercle bacilli with IgG3 against LAM antigen [28] enhanced the granulomatous infiltration and prolonged the survival of mice, without affecting the bacterial load in the lungs, while an intravenously administered IgG1 against the same antigen decreased the bacterial load, and also prolonged survival [29]. The authors of both these studies suggested that antibody action involved blocking of the LAM-mediated uptake of bacilli by macrophages.

Another study, utilising an antibody against heparin-binding hemagglutinin (HBHA) glycoprotein, showed impaired bacterial dissemination from the lungs, due to the antibody inhibiting HBHA interaction with epithelial cells [30]. In addition to the above quoted passive protection studies, in vitro coating of $M$. tuberculosis bacilli with monoclonal antilipomannan IgG3 [28] or anti-MPB83 surface glycoprotein IgG1 [31] prolonged the survival (but not the infection of lungs) of infected mice. 
Taken together, these studies have clearly demonstrated that antibodies can influence $M$. tuberculosis infection, despite the intracellular location, by probably interacting with the bacilli during the extracellular phase following the initial inhalation, or the release from apoptotic macrophages. No clinical trials have been conducted as yet, but they seem justified, subject to development and evaluation of 'humanised' mAbs.

\section{Immunotherapy of TB with mouse IgA mAb TBA61}

IgA is the most abundant antibody class in mucosal fluids, where it plays important antimicrobial roles involving several different mechanisms of action. The majority of the IgA found in mucosal fluids is secretory $\operatorname{IgA}(\operatorname{sig} \mathrm{A})$, which is formed when polymeric IgA binds to the poly-immunoglobulin receptor (PIGR), expressed on the basolateral side of epithelial membranes. While retaining a portion of PIGR, the antibody is then translocated into the mucosal lumen, where it can bind to invading pathogens, leading to their neutralisation or 'exclusion' of infection. sIgA can also intercept viruses infecting epithelial cells, during the process of antibody transcytosis [32]. These important functions of sIgA, coupled with its increased stability in harsh mucosal environment, make this form of IgA antibody particularly suitable for therapeutic purposes. Unfortunately, $\operatorname{sg} A$ is difficult to make in recombinant form, though advances in expression technology have been made [33]. Therefore, most of the passive protection studies have been conducted with the serum forms of monomeric IgA.

IgA can bind to a number of different cellular receptors. In addition to the already mentioned PIGR on epithelial cells, the main Fc receptor of mononuclear cells for human IgA is CD89, though its mouse equivalent has not been identified. Other known IgA receptors include the asialoglycoprotein receptor, which plays a role in IgA catabolism by hepatocytes [34], the transferrin receptor, which binds IgA1 but not IgA2 [35] and the $\operatorname{IgA} / \operatorname{IgM}$ receptor $(\mathrm{Fc} \alpha / \mu \mathrm{R})$, which is expressed on B cells and monocytes [36].

IgA was reported to be protective against pathogenic bacteria in a number of studies, although the mechanisms of action appear different. For example, immune exclusion was reported as the key protective mechanism against Salmonella typhimurium [37] and Vibrio cholera [38], while agglutination was shown to play a role in inhibition of Chlamydia trachomatis genital infection [39]. In addition, binding to a defined virulence factor and neutralisation, were the mechanisms of inhibition of Helicobacter felis gastric infection [40], while multiple mechanisms were suggested for IgA-mediated inhibition of Shigella flexneri infection [41].

Transmission of mAbs against mycobacterial antigens into the lungs following intranasal (i.n.) or parenteral administration [42] was more efficient for IgA, than for IgG mAbs. When comparing these $\mathrm{mAbs}$ for their protective capacity in BALB/c mouse model of $M$. tuberculosis infection, the IgA mAb TBA61, which is specific for the $a$-crystallin (Acr, $16 \mathrm{kDa}$ ) antigen, was superior to both an IgG1 of the same antigen and epitope specificity, and also to another IgA mAb, specific for the PstS1 (38 kDa) antigen [43]. Both monomeric and polymeric form of IgA were found to be protective, inducing an approximately 10-fold reduction of the bacterial load in infected animals. Interestingly, both pre- and postchallenge $\mathrm{mAb}$ inoculations were required for optimal protection and the Acr antigen specificity and IgA isotype were both important for the observed inhibitory effect [43]. 
Acr is a small heat shock protein of M. tuberculosis which is expressed at particularly high levels during conditions of anoxia and stress during growth in macrophages [44, 45]. Although the protein is largely expressed in the cytosol, an increased association with the bacterial cell wall is observed under the conditions of stress and low oxygen concentration [46]. These conditions are present during the stationary phase of growth in vitro and also during the intracellular phase of infection. The recent evidence suggests that $M$. tuberculosis clinical strains recovered from the sputum of TB patients have a changed phenotype consistent with stationary, rather than actively dividing organisms [47], lending further support to the importance of the Acr antigens as the antibody target. Evidence from the guinea pig model of $M$. tuberculosis infection indicates that the majority of residual 'persister' bacilli following short-term drug treatment are extracellular [48]. Most likely, such non-dividing organisms would express high levels of cell wall associated Acr, making them a suitable target for anti-Acr IgA mAbs.

The IgA-mediated inhibition of the early M. tuberculosis infection in mice was transient, and therefore we explored the possibilities for extending and further enhancing the observed therapeutic effect. Cytokines play crucial roles in modulating immune responses to infection, and therefore, could be harnessed to aid therapeutic treatments. We considered the immune-stimulating cytokine IFN- $\gamma$, and the suppression/removal of Th2 cytokine IL-4, that can undermine protective immunity in TB. The rationale for inclusion of IFN- $\gamma$ and also the neutralising anti-IL-4 antibodies, as well as the effect of combined immunotherapy is described in the following section.

\section{Combined immunotherapy for TB with IgA, IFN- $\gamma$ and anti-IL-4}

\subsection{Rationale for IFN- $\gamma$}

IFN- $\gamma$ has many important activities, such as activation of phagocytes, stimulation of antigen presentation, induction of cell proliferation and cell adhesion, and regulation of apoptosis. These important roles of IFN- $\gamma$ for the immune responses to pathogens are best described in the context of the so-called Th1/Th2 paradigm. IL-12, another important cytokine, directly induces IFN- $\gamma$ gene transcription and secretion in antigen-stimulated naive CD4 ${ }^{+}$cells [49], while in turn, IFN- $\gamma$ induces IL-12 expression in macrophages and monocytes [50], thus creating a positive feedback loop. This leads against a Th1 type immune response to an intracellular infection. In contrast, Th2 cytokines IL-4, IL-13 and IL-10 suppress production of IL-12 by monocytes, and consequently also inhibit effector functions of IFN- $\gamma$, notably, the expression of inducible nitric oxide synthase [51,52] and the respiratory burst [53].

The critical role of IFN- $\gamma$ in the immunity to mycobacterial infections was confirmed in IFN- $\gamma$ deficient mice, when two groups showed independently $[54,55]$ that mice with a disrupted IFN- $\gamma$ gene were unable to control $M$. tuberculosis infection. The lack of protective immunity in IFN- $\gamma$ deficient mice could be attributed exclusively to their inability to activate macrophages, since these mice otherwise developed antigen specific $\mathrm{T}$ cell responses, albeit more rapidly than the control mice [56]. Humans with a mutation in the IFN- $\gamma$ receptor show enhanced susceptibility to TB [57] and the results of a first small scale clinical trial for treatment of MDR-TB with aerosolised IFN- $\gamma$ [58] indicated a short-term treatment benefit. Therefore, IFN- $\gamma$ may have a therapeutic potential for treatment of TB, although additional components may be required to achieve a more robust therapeutic effect [59]. 


\subsection{Rationale for Th2-suppressing agents}

The regulatory and potentially detrimental role of Th2 cytokines in TB has recently attracted considerable research interest, in relation to studies of both immunopathogenesis of TB and vaccine development. TB develops only in a small proportion $(5-10 \%)$ of the exposed immunocompetent individuals. It is tempting to speculate that these individuals could have the normally protective innate and acquired immunity 'dis-regulated' by Th2 cell mediated inhibitory immune mechanisms. It has been proposed that IL-4 in particular, could downregulate the protective Th1 cytokine IFN- $\gamma$ and lead to mediated toxicity and fibrosis [60].

However, the exact mechanism of the negative IL-4 effect on the course of mycobacterial infection is not fully understood. One possibility is that IL-4 inhibits the expression of nitric oxide synthase [61, 62] and since nitric oxide is a mandatory mediator of macrophage activation mediated killing of tubercle bacilli, its decreased levels could delay the clearance of mycobacterial infection [52].

Additional circumstantial evidence from experimental studies also points to a possible negative role of IL- 4 in TB. Thus, $\beta$-glucan mediated inhibition of TGF- $\beta$, resulted in upregulated expression of IFN- $\gamma$ and IL-2 and downregulated production of IL-4, leading to a significant reduction in bacterial counts in the absence of chemotherapy [63]. This was unfortunately associated with an increased risk of inflammation in the lungs, which required anti-inflammatory treatment for optimal anti-tuberculous effect.

Similarly, immunisation of $M$. tuberculosis infected mice with heat-killed $M$. vaccae resulted in decrease of bacterial burden in the lungs, which was correlated by decrease in IL-4 expression [64]. Two other immunotherapeutic vaccines have been proposed (though not tested in clinical trials), both interfering with Th2 cytokine expression levels. A DNA vaccine incorporating mycobacterial heat shock protein 65 (HSP65) was shown to be protective in mice [6] and the protection was clearly correlated with down-regulation of IL-4 production. More recently, a fragmented and detoxified $M$. tuberculosis based vaccine termed RUTI, was shown to be protective when given to chemotherapy-treated mice [9], and this effect was at least in part mediated by suppression of Th2 cytokine activity. Therefore, therapeutic approaches targeting Th2 cytokines could potentially be utilised for adjunctive treatment of TB.

\section{Development and testing of CIT}

IgA-mediated protection against early $M$. tuberculosis in mice could be further extended by co-inoculation with IFN- $\gamma[65,66]$. IFN- $\gamma$ was inoculated to mice i.n., 3 days before aerosol M. tuberculosis challenge, and then again together with $\operatorname{IgA} \mathrm{mAb}$, on the day of the infection and 2 days later. Co-administration of $\operatorname{IgA}$ and IFN- $\gamma$ synergistically prolonged and enhanced the CFU-inhibitory effect of IgA alone and also reduced lung pathology [65].

IL-4 depleted or genetically deficient IL-4\%- mice are more resistant to $M$. tuberculosis infection; this could be reversed by reconstitution of mice with recombinant IL-4 [67, 68]. Combined treatment of mice with a neutralizing anti-IL- 4 antibody, anti- $\alpha$-crystallin IgA $\mathrm{mAb}$ and IFN- $\gamma$ reduced lung infection with $M$. tuberculosis profoundly more than individual treatment regimens. Most importantly, however, this combined triple treatment with anti-IL-4 mAb, IgA and IFN- $\gamma$, prevented post-chemotherapy relapse of the infection in 
three different strains of mice [69], suggesting that CIT has the therapeutic potential for adjunctive application with standard TB treatment.

Multiple mechanisms are likely to be involved in protection against $M$. tuberculosis conferred by CIT. Some of them may operate on a cellular level (for example, stimulation of phagocytosis by IgA and IFN- $\gamma$ ), while others may involve more complex interactions within the immune system, resulting in modulation of the early response to $M$. tuberculosis infection. A schematic representation of some of the potential mechanisms of CIT action is depicted in Fig.1.

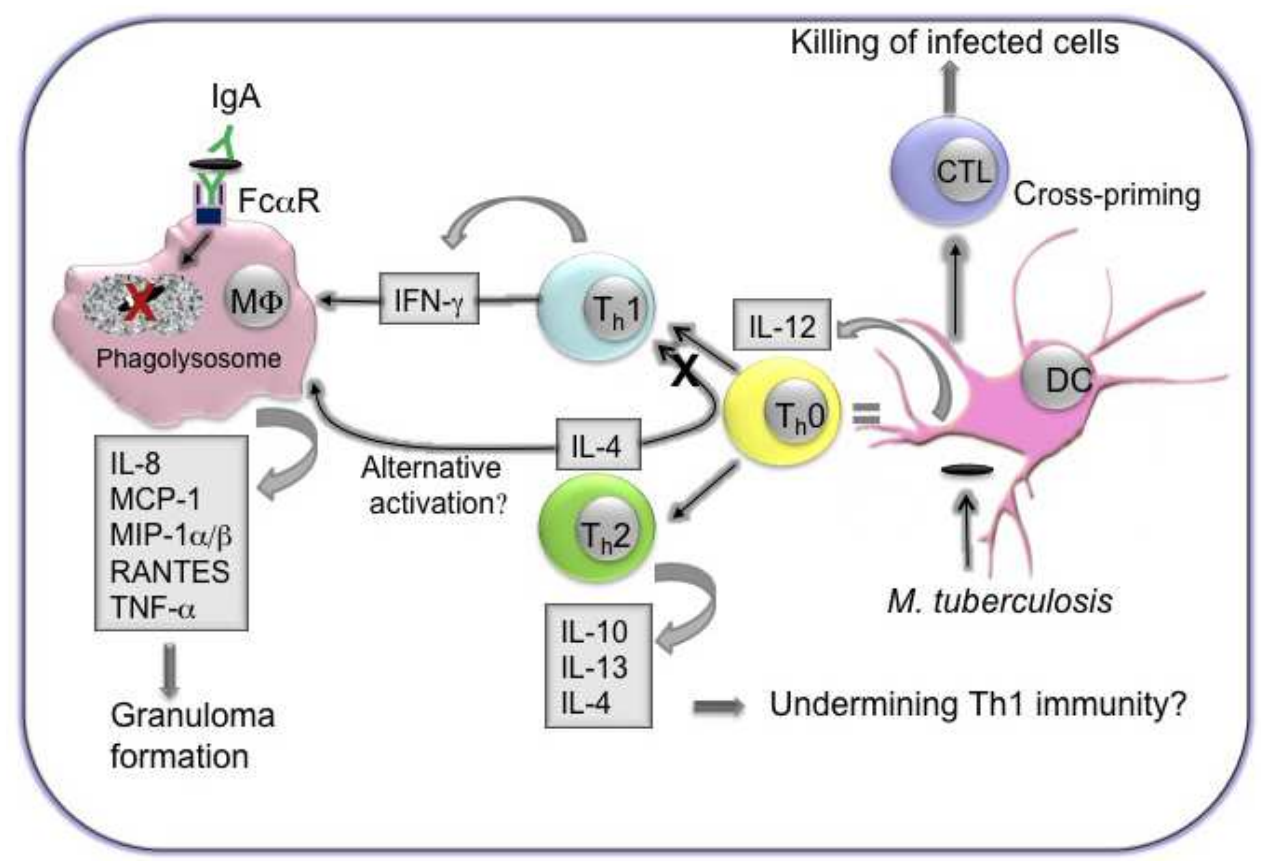

Fig. 1. Proposed mechanisms of action of combined immunotherapy (CIT) in M. tuberculosis infected hosts. Antibody could target extracellular bacteria and following their phagocytosis via IgA-receptor (indicated is human FcaR, though the mouse equivalent is not known), the bacilli are destroyed in phagolysosome. IFN- $\gamma$ activates non-infected monocytes/macrophages, thus enhancing their bactericidal activity towards incipient infection. IL-4 could induce alternative activation of macrophages that does not lead to killing of intracellular organisms; in addition, it could also negatively modulate the early immune response to $M$. tuberculosis, by undermining the Th1 type response. Other, unknown mechanisms might also be involved, possibly including cytotoxicity of lymphocytes and granuloma formation.

\section{Translational studies with human IgA}

In order to further develop the combined TB immunotherapy for potential application in humans, a human IgA antibody specific for Acr antigen has been generated. As mentioned 
earlier, the human and mouse IgA systems differ significantly, both in terms of $\operatorname{IgA}$ structure and also the availability of IgA Fc receptors. Thus, IgA exists in two forms in humans, IgA1 and IgA2, while the mouse IgA exists in a single form, corresponding to IgA1. The most significant difference, however, is that there is a well characterised IgA-Fc receptor on human myeloid cells, CD89, which is responsible for much of the IgA-mediated antimicrobial activity [70-72], while an equivalent receptor in mice has not be identified. Therefore, it is an important consideration that therapeutic recombinant IgA antibodies should bind efficiently not only to the target antigen, but also to CD89 on monocytes/macrophages, the target cell population for immunotherapy.

A single chain $\mathrm{Fv}$ fragment ( $\mathrm{scFv}$ ) specific for Acr was generated using a human phage library and then expressed in $\mathrm{CHO}$ cells as a human IgA1 molecule with 'grafted' scFv epitope binding site [73]. The expressed $170 \mathrm{kDa}$ recombinant IgA was purified by affinity chromatography and found to be glycosylated, with both $\mathrm{N}$ - and O-linked sugars present. The purified human antibody, termed 2E9IgA1, bound to both Acr $\left(7.0 \times 10^{-8}\right)$ and CD89 $\left(2.9 \times 10^{-6}\right)$, with both the affinity constants being well within the range for antibody-antigen and antibody-receptor type interactions, respectively.

The effect of 2E9IgA1 on M. tuberculosis infection was tested in mice transgenic for the human IgA receptor. Antibody was administered at the time of infection and again, at either 1 or 21 day after infection. Separate groups of mice were inoculated with IFN- $\gamma$ or with both IFN- $\gamma$ and IgA. The bacterial load in the lungs and spleen, as well as the immunopathology of the lungs were analysed four weeks later. Both 2E9IgA1 and IFN- $\gamma$ caused partial reduction in bacterial load, but the greatest therapeutic effect was observed when the two were co-administered together, with the difference between treated and untreated animals being statistically highly significant [73]. Early and late treatment applications following challenge of mice with $M$. tuberculosis produced a similar therapeutic effect. Importantly though, the treatment had no significant effect on the infection in non-transgenic littermate controls, suggesting a mandatory role for CD89 in the observed reduction of infection. In agreement with decreased bacterial load in the lungs, the treated animals showed also reduced granulomatous infiltration of their lungs.

Studies on whole human blood cultures infected with $M$. tuberculosis showed that 2E9IgA1 reduced the infection at least in some donors. This effect required a relatively high concentration of the antibody $(100 \mu \mathrm{g} / \mathrm{ml})$ and the inhibition was apparent only when the ratio of bacteria:cell was 10 or less [73]. Interestingly, IFN- $\gamma$ did not enhance the bactericidal effect of 2E9IgA in whole blood cultures although it did do so in purified human monocytes infected with $M$. tuberculosis. The outcome of the in vitro studies is generally consistent with the finding using mouse $\operatorname{IgA}$, that the therapeutic effect in vivo was greater than the inhibition of infection in vitro, hence suggesting the involvement of complex in vivo mechanisms of antibody action.

These studies showed that the therapeutic potentials of 2E9IgA1 human mAb for tuberculosis deserve further evaluation in the form of CIT for treatment. The history of the past advances using IgA based CIT are summarised in Table 1. 


\begin{tabular}{|c|c|c|}
\hline Year & Stage of development & Reference \\
\hline 2000 & $\begin{array}{l}\text { TBA61 anti-Acr mAb generated and shown to be superior to } \\
\text { IgG for transmission to lungs }\end{array}$ & {$[42]$} \\
\hline 2004 & $\begin{array}{l}\text { TBA61 IgA induced a 10-fold inhibition of early } M \text {. } \\
\text { tuberculosis infection in BALB/c mice; however, inhibition } \\
\text { was transient }\end{array}$ & [43] \\
\hline 2006 & $\begin{array}{l}\text { Co-administration of IgA and IFN- } \gamma \text { extended the duration } \\
\text { of inhibition compared to IgA alone }\end{array}$ & [65] \\
\hline 2007 & $\begin{array}{l}\text { Addition of anti-IL-4 antibody profoundly enhanced the } \\
\text { therapeutic effect of IgA and IFN- } \gamma\end{array}$ & [67] \\
\hline 2009 & $\begin{array}{l}\text { CIT (IgA, IFN- } \gamma \text { and anti-IL4) reduced significantly } \\
\text { postchemotherapy relapse of } M \text {. tuberculosis infection in } \\
\text { mice }\end{array}$ & [69] \\
\hline 2011 & $\begin{array}{l}\text { Human 2E9IgA1 anti-Acr mAb generated and shown to be } \\
\text { protective, when co-administered with IFN- } \gamma \text {, in human IgA- } \\
\text { receptor transgenic mice }\end{array}$ & [73] \\
\hline $\begin{array}{l}\text { Future } \\
\text { research }\end{array}$ & $\begin{array}{l}\text { Testing of 2E9IgA1-based CIT in non-human primates and } \\
\text { subsequently, phase I human clinical trials }\end{array}$ & - \\
\hline
\end{tabular}

Table 1. Key stages of development of CIT based on IgA, IFN- $\gamma$ and anti-IL-4

\section{Targets for future research, development and clinical evaluation}

There is scope for future research on the following different aspects of the combined immunotherapy:

1. Mechanisms of IgA action. We proposed previously that binding of mouse IgA to the intracellular lectin galectin 3 [74], which accumulates in phagosomes [75], could 'unblock' the M. tuberculosis induced inhibition of phagosome maturation [19]. In principle, galectin 3 could act as a mediator of the intracellular actions of IgA, considering that it has structural homology with TRIM21, which mediates the virus neutralizing activity of IgG antibodies [76].

2. Studies in CD89 transgenic mice. There is a need to demonstrate: i) if there is synergy between the actions of the 2E9IgA human antibody and anti-IL-4 antibodies or IL-4 antagonists; ii) if 2E9IgA based CIT can reduce the relapse of infection following shortterm chemotherapy to an extent, which had been reported for the mouse TBA61-based CIT; iii) if CIT can reduce the MDR-TB infection.

3. Development of 2E9IgA production. It is necessary to modify the plastic adherent CHO-K1 transfectant cell line into a suspension growing variant [77], in order to increase the yield of IgA production. This is a prerequisite for producing the GMP-grade antibody in quantities required for evaluation in clinical trials.

4. Evaluation of 2E9IgA based CIT in non-human monkey models of TB. Macaques are eminently suitable, since they express the IgA/CD89 receptor [78] that can bind human IgA [79]. A suitable technique for aerosol delivery of IgA would need to be developed 
using the approaches for the inhaled therapy with various agents [80]. Demonstrating protection against aerosol $M$. tuberculosis infection and pathology in the macaque model of infection would justify further evaluation in human clinical trials.

5. Evaluation in HIV-positive, low $C D 4^{+}$cell patients. They develop active $\mathrm{TB}$ at a high rate and need an alternative to the current combined chemotherapy for HIV and TB [81], because it associates with drug-drug interactions and toxicity.

6. Evaluation in patients with drug-susceptible $T B$, as an adjunct to chemotherapy. The potential benefit to the widest range of patients would be to shorten the duration of treatment. This would in turn lead to higher completion rates, reduced risk of relapse and MDRTB. The rationale of this approach has recently been strengthened by the finding, that chemotherapy generated 'persister' bacilli are extracellular [48]; this makes them a suitable target for IgA-based CIT.

7. Evaluation in MDR-TB and XDR-TB patients. Existing difficulties in developing effective new drugs justify evaluation of CIT as a possible alternative approach.

\section{References}

[1] Andries K, Verhasselt P, Guillemont J, et al. A diarylquinoline drug active on the ATP synthase of Mycobacterium tuberculosis. Science 2005;307:223-7.

[2] Onyebujoh PC, Abdulmumini T, Robinson S, Rook GAW, Stanford JL. Immunotherapy with Mycobacterium-Vaccae As An Addition to Chemotherapy for the Treatment of Pulmonary Tuberculosis Under Difficult Conditions in Africa. Respiratory Medicine 1995;89:199-207.

[3] Stanford J, Stanford C, Grange J. Immunotherapy with Mycobacterium vaccae in the treatment of tuberculosis. Frontiers in Bioscience 2004;9:1701-19.

[4] Mwinga A, Nunn A, Ngwira B, et al. Mycobacterium vaccae (SRL172) immunotherapy as an adjunct to standard antituberculosis treatment in HIV-infected adults with pulmonary tuberculosis: a randomised placebo-controlled trial. Lancet 2002;360:1050-5.

[5] Johnson JL, Nunn AJ, Fourie PB, et al. Effect of Mycobacterium vaccae (SRL172) immunotherapy on radiographic healing in tuberculosis. International Journal of Tuberculosis and Lung Disease 2004;8:1348-54.

[6] Lowrie DB, Tascon RE, Bonato VLD, et al. Therapy of tuberculosis in mice by DNA vaccination. Nature 1999;400:269-71.

[7] Ha SJ, Jeon BY, Kim SC, et al. Therapeutic effect of DNA vaccines combined with chemotherapy in a latent infection model after aerosol infection of mice with Mycobacterium tuberculosis. Gene Therapy 2003;10:1592-9.

[8] Turner J, Rhoades ER, Keen M, Belisle JT, Frank AA, Orme IM. Effective preexposure tuberculosis vaccines fail to protect when they are given in an immunotherapeutic mode. Infection and Immunity 2000;68:1706-9.

[9] Cardona PJ, Arnat I, Gordillo S, et al. Immunotherapy with fragmented Mycobacterium tuberculosis cells increases the effectiveness of chemotherapy against a chronical infection in a murine model of tuberculosis. Vaccine 2005;23:1393-8. 
[10] Toossi Z, Ellner JJ. Interaction of Leu-11 Reactive Lymphocytes and Adherent Cells in Suppression of Ppd-Induced Il-2 Production in Tuberculosis. Clinical Research 1986;34:A535.

[11] Vankayalapati R, Wizel B, Weis SE, et al. Serum cytokine concentrations do not parallel Mycobacterium tuberculosis - Induced cytokine production in patients with tuberculosis. Clinical Infectious Diseases 2003;36:24-8.

[12] Johnson BJ, Bekker LG, Rickman R, et al. rhuIL-2 adjunctive therapy in multidrug resistant tuberculosis: a comparison of two treatment regimens and placebo. Tubercle and Lung Disease 1997;78:195-203.

[13] Johnson BJ, Ress SR, Willcox P, et al. Clinical and Immune-Responses of Tuberculosis Patients Treated with Low-Dose Il-2 and Multidrug Therapy. Cytokines and Molecular Therapy 1995;1:185-96.

[14] Barnes PF. Immunotherapy for tuberculosis - Wave of the future or tilting at windmills? American Journal of Respiratory and Critical Care Medicine 2003;168:142-3.

[15] Glatman-Freedman A. Advances in antibody-mediated immunity against Mycobacterium tuberculosis: implications for a novel vaccine strategy. Fems Immunology and Medical Microbiology 2003;39:9-16.

[16] Mukherjee J, Scharff MD, Casadevall A. Protective Murine Monoclonal-Antibodies to Cryptococcus-Neoformans. Infection and Immunity 1992;60:4534-41.

[17] Edelson BT, Unanue ER. Intracellular antibody neutralizes Listeria growth. Immunity 2001;14:503-12.

[18] Li JSY, Yager E, Reilly M, et al. Outer membrane protein-specific monoclonal antibodies protect SCID mice from fatal infection by the obligate intracellular bacterial pathogen Ehrlichia chaffeensis. Journal of Immunology 2001;166:185562.

[19] Reljic R, Williams A, Ivanyi J. Mucosal immunotherapy of tuberculosis: Is there value in passive IgA? Tuberculosis 2006;86:179-90.

[20] Casadevall A. Antibody-mediated immunity against intracellular pathogens: Two-dimensional thinking comes full circle. Infection and Immunity 2003;71:4225-8.

[21] Costello AMD, Kumar A, Narayan V, et al. Does Antibody to Mycobacterial Antigens, Including Lipoarabinomannan, Limit Dissemination in Childhood Tuberculosis. Transactions of the Royal Society of Tropical Medicine and Hygiene 1992;86:68692.

[22] Sanchez-Rodriguez C, Estrada-Chavez C, Garcia-Vigil J, et al. An IgG antibody response to the antigen 85 complex is associated with good outcome in Mexican Totonaca Indians with pulmonary tuberculosis. International Journal of Tuberculosis and Lung Disease 2002;6:706-12.

[23] Vordermeier HM, Venkatprasad N, Harris DP, Ivanyi J. Increase of tuberculous infection in the organs of $\mathrm{B}$ cell-deficient mice. Clinical and Experimental Immunology 1996;106:312-6.

[24] Rodriguez A, Tjarnlund A, Ivanji J, et al. Role of IgA in the defense against respiratory infections IgA deficient mice exhibited increased susceptibility to intranasal infection with Mycobacterium bovis BCG. Vaccine 2005;23:2565-72. 
[25] Guirado E, Amat I, Gil O, et al. Passive serum therapy with polyclonal antibodies against Mycobacterium tuberculosis protects against post-chemotherapy relapse of tuberculosis infection in SCID mice. Microbes and Infection 2006;8:1252-9.

[26] Roy E, Stavropoulos E, Brennan J, et al. Therapeutic efficacy of high-dose intravenous immunoglobulin in Mycobacterium tuberculosis infection in mice. Infection and Immunity 2005;73:6101-9.

[27] Jackett PS, Bothamley GH, Batra HV, Mistry A, Young DB, Ivanyi J. Specificity of Antibodies to Immunodominant Mycobacterial Antigens in Pulmonary Tuberculosis. Journal of Clinical Microbiology 1988;26:2313-8.

[28] Teitelbaum R, Glatman-Freedman A, Chen B, et al. A mAb recognizing a surface antigen of Mycobacterium tuberculosis enhances host survival. Proceedings of the National Academy of Sciences of the United States of America 1998;95:1568893.

[29] Hamasur B, Haile M, Pawlowski A, Schroder U, Kallenius G, Svenson SB. A mycobacterial lipoarabinomannan specific monoclonal antibody and its $F(a b$ ')(2) fragment prolong survival of mice infected with Mycobacterium tuberculosis. Clinical and Experimental Immunology 2004;138:30-8.

[30] Pethe K, Alonso S, Biet F, et al. The heparin-binding haemagglutinin of M-tuberculosis is required for extrapulmonary dissemination. Nature 2001;412:190-4.

[31] Chambers MA, Gavier-Widen D, Hewinson RG. Antibody bound to the surface antigen MPB83 of Mycobacterium bovis enhances survival against high dose and low dose challenge. Fems Immunology and Medical Microbiology 2004;41:93-100.

[32] Mazanec MB, Kaetzel CS, Lamm ME, Fletcher D, Nedrud JG. Intracellular Neutralization of Virus by Immunoglobulin-A Antibodies. Proceedings of the National Academy of Sciences of the United States of America 1992;89:6901-5.

[33] Crottet P, Cottet S, Corthesy B. Expression, purification and biochemical characterization of recombinant murine secretary component: a novel tool in mucosal immunology. Biochemical Journal 1999;341:299-306.

[34] Stockert RJ, Kressner MS, Collins JC, Sternlieb I, Morell AG. Iga Interaction with the Asialoglycoprotein Receptor. Proceedings of the National Academy of Sciences of the United States of America-Biological Sciences 1982;79:6229-31.

[35] Moura IC, Centelles MN, Arcos-Fajardo M, et al. Identification of the transferrin receptor as a novel immunoglobulin (Ig)A1 receptor and its enhanced expression on mesangial cells in IgA nephropathy. Journal of Experimental Medicine 2001;194:417-25.

[36] Shibuya A, Sakamoto N, Shimizu Y, et al. Fc alpha/mu receptor mediates endocytosis of IgM-coated microbes. Nature Immunology 2000;1:441-6.

[37] Michetti P, Mahan MJ, Slauch JM, Mekalanos JJ, Neutra MR. Monoclonal Secretory Immunoglobulin-A Protects Mice Against Oral Challenge with the Invasive Pathogen Salmonella-Typhimurium. Infection and Immunity 1992;60:1786-92.

[38] Apter FM, Michetti P, Winner LS, Mack JA, Mekalanos JJ, Neutra MR. Analysis of the Roles of Antilipopolysaccharide and Anticholera Toxin Immunoglobulin A 
(Iga) Antibodies in Protection Against Vibrio-Cholerae and Cholera-Toxin by Use of Monoclonal Iga Antibodies In-Vivo. Infection and Immunity 1993;61:5279-85.

[39] Pal S, Theodor I, Peterson EM, delaMaza LM. Monoclonal immunoglobulin A antibody to the major outer membrane protein of the Chlamydia trachomatis mouse pneumonitis biovar protects mice against a chlamydial genital challenge. Vaccine 1997;15:575-82.

[40] Blanchard TG, Czinn SJ, Maurer R, Thomas WD, Soman G, Nedrud JG. Urease-Specific Monoclonal-Antibodies Prevent Helicobacter-Felis Infection in Mice. Infection and Immunity 1995;63:1394-9.

[41] Phalipon A, Kaufmann M, Michetti P, et al. Monoclonal Immunoglobulin-A AntibodyDirected Against Serotype-Specific Epitope of Shigella-Flexneri Lipopolysaccharide Protects Against Murine Experimental Shigellosis. Journal of Experimental Medicine 1995;182:769-78.

[42] Falero-Diaz G, Challacombe S, Rahman D, et al. Transmission of IgA and IgG monoclonal antibodies to mucosal fluids following intranasal or parenteral delivery. International Archives of Allergy and Immunology 2000;122:143-50.

[43] Williams A, Reljic R, Naylor I, et al. Passive protection with immunoglobulin A antibodies against tuberculous early infection of the lungs. Immunology 2004;111:328-33.

[44] Sherman DR, Voskuil M, Schnappinger D, Liao RL, Harrell MI, Schoolnik GK. Regulation of the Mycobacterium tuberculosis hypoxic response gene encoding alpha-crystallin. Proceedings of the National Academy of Sciences of the United States of America 2001;98:7534-9.

[45] Yuan Y, Crane DD, Simpson RM, et al. The 16-kDa alpha-crystallin (Acr) protein of Mycobacterium tuberculosis is required for growth in macrophages. Proceedings of the National Academy of Sciences of the United States of America 1998;95:9578-83.

[46] Cunningham AF, Spreadbury CL. Mycobacterial stationary phase induced by low oxygen tension: Cell wall thickening and localization of the 16-kilodalton alphacrystallin homology. Journal of Bacteriology 1998;180:801-8.

[47] Garton NJ, Waddell SJ, Sherratt AL, et al. Cytological and transcript analyses reveal fat and lazy persister-like bacilli in tuberculous sputum. Plos Medicine 2008;5:634-45.

[48] Lenaerts AJ, Hoff D, Aly S, et al. Location of persisting mycobacteria in a guinea pig model of tuberculosis revealed by R207910. Antimicrobial Agents and Chemotherapy 2007;51:3338-45.

[49] Lederer JA, Perez VL, DesRoches L, Kim SM, Abbas AK, Lichtman AH. Cytokine transcriptional events during helper $\mathrm{T}$ cell subset differentiation. Journal of Experimental Medicine 1996;184:397-406.

[50] Yoshida A, Koide Y, Uchijima M, Yoshida TO. Ifn-Gamma Induces Il-12 Messenger-Rna Expression by A Murine Macrophage Cell-Line, J774. Biochemical and Biophysical Research Communications 1994;198:857-61. 
[51] Liew FY, Li Y, Severn A, et al. A Possible Novel Pathway of Regulation by Murine THelper Type-2 (Th2) Cells of A Th1 Cell-Activity Via the Modulation of the Induction of Nitric-Oxide Synthase on Macrophages. European Journal of Immunology 1991;21:2489-94.

[52] Reljic R, Stylianou E, Balu S, Ma JK. Cytokine interactions that determine the outcome of mycobacterial infection of macrophages. Cytokine 2010;51:42-6.

[53] Lehn M, Weiser WY, Engelhorn S, Gillis S, Remold HG. Il-4 Inhibits H2O2 Production and Antileishmanial Capacity of Human Cultured Monocytes Mediated by IfnGamma. Journal of Immunology 1989;143:3020-4.

[54] Cooper AM, Dalton DK, Stewart TA, Griffin JP, Russell DG, Orme IM. Disseminated Tuberculosis in Interferon-Gamma Gene-Disrupted Mice. Journal of Experimental Medicine 1993;178:2243-7.

[55] Flynn JL, Chan J, Triebold KJ, Dalton DK, Stewart TA, Bloom BR. An Essential Role for Interferon-Gamma in Resistance to Mycobacterium-Tuberculosis Infection. Journal of Experimental Medicine 1993;178:2249-54.

[56] Pearl JE, Saunders B, Ehlers S, Orme IM, Cooper AM. Inflammation and lymphocyte activation during mycobacterial infection in the interferon-gamma-deficient mouse. Cellular Immunology 2001;211:43-50.

[57] Dorman SE, Holland SM. Mutation in the signal-transducing chain of the interferongamma receptor and susceptibility to mycobacterial infection. Journal of Clinical Investigation 1998;101:2364-9.

[58] Condos R, Rom WN, Schluger NW. Treatment of multidrug-resistant pulmonary tuberculosis with interferon-gamma via aerosol. Lancet 1997;349:1513-5.

[59] Reljic R. IFN-gamma therapy of tuberculosis and related infections. Journal of Interferon and Cytokine Research 2007;27:353-63.

[60] Rook GAW, Hernandez-Pando R, Dheda K, Seah GT. IL-4 in tuberculosis: implications for vaccine design. Trends in Immunology 2004;25:483-8.

[61] Bogdan C, Vodovotz Y, Paik J, Xie QW, Nathan C. Interleukin-4 and Transforming Growth Factor-Beta Suppress Inducible Nitric Oxide Synthase by Different Mechanisms. Biology of Nitric Oxide, Pt 4 1994;8:313-6.

[62] Nemoto Y, Otsuka T, Niiro H, et al. Differential effects of interleukin-4 and interleukin10 on nitric oxide production by murine macrophages. Inflammation Research 1999;48:643-50.

[63] Hernandez-Pando R, Orozco-Esteves H, Maldonado HA, et al. A combination of a transforming growth factor-beta antagonist and an inhibitor of cyclooxygenase is an effective treatment for murine pulmonary tuberculosis. Clinical and Experimental Immunology 2006;144:264-72.

[64] Rook GAW, HernandezPando R. The pathogenesis of tuberculosis. Annual Review of Microbiology 1996;50:259-84.

[65] Reljic R, Clark SO, Williams A, et al. Intranasal IFN gamma extends passive IgA antibody protection of mice against Mycobacterium tuberculosis lung infection. Clinical and Experimental Immunology 2006;143:467-73. 
[66] Reljic R, Williams A, Clark S, Marsh P, Ivanyi J. Intranasal IFN gamma and anti alphacrystallin IgA inhibit Mycobacterium tuberculosis lung infection in mice. Immunology 2007;120:43.

[67] Buccheri S, Reljic R, Caccamo N, et al. IL-4 depletion enhances host resistance and passive IgA protection against tuberculosis infection in BALB/c mice. European Journal of Immunology 2007;37:729-37.

[68] Roy E, Lowrie DB, Jolles SR. Current strategies in TB immunotherapy. Current Molecular Medicine 2007;7:373-86.

[69] Buccheri S, Reljic R, Caccamo N, et al. Prevention of the post-chemotherapy relapse of tuberculous infection by combined immunotherapy. Tuberculosis 2009;89:914.

[70] Launay P, Grossetete B, Arcos-Fajardo M, et al. Fc alpha receptor (CD89) mediates the development of immunoglobulin A (IgA) nephropathy (Berger's disease): Evidence for pathogenic soluble receptor-IgA complexes in patients and CD89 transgenic mice. Journal of Experimental Medicine 2000;191:1999-2009.

[71] Otten MA, van Egmond M. The Fc receptor for IgA (Fc alpha RI, CD89). Immunology Letters 2004;92:23-31.

[72] Pleass RJ, Dunlop JI, Anderson CM, Woof JM. Identification of residues in the $\mathrm{CH} 2 / \mathrm{CH} 3$ domain interface of IgA essential for interaction with the human $\mathrm{FC}$ alpha receptor (Fc alpha R) CD89. Journal of Biological Chemistry 1999;274:2350814.

[73] Balu S, Reljic R, Lewis MJ, et al. A Novel Human IgA Monoclonal Antibody Protects against Tuberculosis. Journal of Immunology 2011;186:3113-9.

[74] Reljic R, Crawford C, Challacombe S, Ivanyi J. Mouse monoclonal IgA binds to the galectin-3/Mac-2 lectin from mouse macrophage cell lines. Immunology Letters 2004;93:51-6.

[75] Beatty WL, Rhoades ER, Hsu DK, Liu FT, Russell DG. Association of a macrophage galactoside-binding protein with Mycobacterium-containing phagosomes. Cellular Microbiology 2002;4:167-76.

[76] Mallery DL, McEwan WA, Bidgood SR, Towers GJ, Johnson CM, James LC. Antibodies mediate intracellular immunity through tripartite motif-containing 21 (TRIM21). Proceedings of the National Academy of Sciences of the United States of America 2010;107:19985-90.

[77] Beyer T, Lohse S, Berger S, Peipp M, Valerius T, Dechant M. Serum-free production and purification of chimeric IgA antibodies. Journal of Immunological Methods 2009;346:26-37.

[78] Rogers KA, Scinicariello F, Attanasio R. Identification and characterization of macaque CD89 (immunoglobulin A Fc receptor). Immunology 2004;113:178-86.

[79] Rogers KA, Jayashankar L, Scinicariello F, Attanasio R. Nonhuman primate IgA: Genetic heterogeneity and interactions with CD89. Journal of Immunology 2008;180:4816-24.

[80] Misra A, Hickey AJ, Rossi C, et al. Inhaled drug therapy for treatment of tuberculosis. Tuberculosis 2011;91:71-81. 
[81] Reljic R, Ivanyi J. A case for passive immunoprophylaxis against tuberculosis. Lancet Infectious Diseases 2006;6:813-8. 


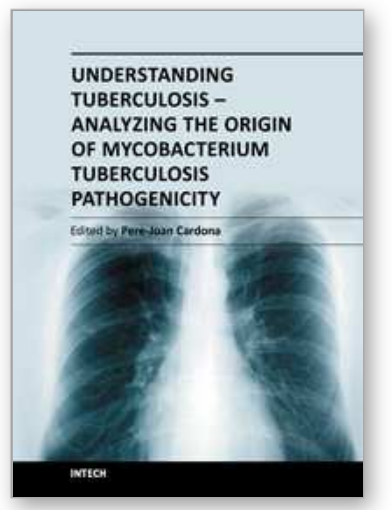

\section{Understanding Tuberculosis - Analyzing the Origin of Mycobacterium Tuberculosis Pathogenicity \\ Edited by Dr. Pere-Joan Cardona}

ISBN 978-953-307-942-4

Hard cover, 560 pages

Publisher InTech

Published online 24, February, 2012

Published in print edition February, 2012

Mycobacterium tuberculosis in an attempt to understand the extent to which the bacilli has adapted itself to the host and to its final target. On the other hand, there is a section in which other specialists discuss how to manipulate this immune response to obtain innovative prophylactic and therapeutic approaches to truncate the intimal co-evolution between Mycobacterium tuberculosis and the Homo sapiens.

\section{How to reference}

In order to correctly reference this scholarly work, feel free to copy and paste the following:

Rajko Reljic and Juraj Ivanyi (2012). Immunotherapy of Tuberculosis with IgA and Cytokines, Understanding Tuberculosis - Analyzing the Origin of Mycobacterium Tuberculosis Pathogenicity, Dr. Pere-Joan Cardona (Ed.), ISBN: 978-953-307-942-4, InTech, Available from: http://www.intechopen.com/books/understandingtuberculosis-analyzing-the-origin-of-mycobacterium-tuberculosis-pathogenicity/immunotherapy-oftuberculosis-with-iga-and-cytokines

\section{INTECH}

open science | open minds

\section{InTech Europe}

University Campus STeP Ri

Slavka Krautzeka 83/A

51000 Rijeka, Croatia

Phone: +385 (51) 770447

Fax: +385 (51) 686166

www.intechopen.com

\section{InTech China}

Unit 405, Office Block, Hotel Equatorial Shanghai

No.65, Yan An Road (West), Shanghai, 200040, China

中国上海市延安西路65号上海国际贵都大饭店办公楼 405 单元

Phone: +86-21-62489820

Fax: $+86-21-62489821$ 
(C) 2012 The Author(s). Licensee IntechOpen. This is an open access article distributed under the terms of the Creative Commons Attribution 3.0 License, which permits unrestricted use, distribution, and reproduction in any medium, provided the original work is properly cited. 